\title{
Impact of a medical university on laparoscopic surgery in a service-oriented public hospital in the Caribbean
}

\author{
Shamir O Cawich' \\ Suresh Pooran ${ }^{2}$ \\ Barbara Amow ${ }^{2}$ \\ Ernest $\mathrm{Ali}^{2}$ \\ Fawwaz Mohammed' \\ Marlon Mencia' \\ Samuel Ramsewak' \\ Seetharaman Hariharan' \\ Vijay Naraynsingh' \\ 'Department of Clinical Surgical \\ Sciences, University of the West \\ Indies, St Augustine, ${ }^{2}$ North West \\ Regional Health Authority, Port \\ of Spain General Hospital, Port of \\ Spain, Trinidad and Tobago
}

This article was published in the following Dove Press journal:

Risk Management and Healthcare Policy

16 November 2016

Number of times this article has been viewed

Introduction: The Caribbean lags behind global trends for volume and complexity of laparoscopic operations. In an attempt to promote laparoscopy at a single facility, a partnership was formed between the University of the West Indies (UWI) and the Port of Spain General Hospital in Trinidad and Tobago. This study seeks to document the effect of this partnership on laparoscopic practice.

Materials and methods: In this partnership, the UWI took the bold step of volunteering to staff a surgical team if the Ministry of Health provided the necessary legislative changes. On August 1, 2013, a UWI team was introduced with a mandate to optimize teaching and promote laparoscopic surgery. The UWI team had a similar staff complement to the existing serviceoriented teams. There was no immediate investment in equipment, hospital beds, ICU beds, or operating room space. Therefore, the new team was introduced with limited change in existing conditions, resources, and equipment.

Results: There were 252 laparoscopic operations performed over the study period. After introduction of the UWI team, there was an increase in the mean number of unselected laparoscopic operations ( 3.17 vs 10.83 cases per month; $P<0.001$; $95 \%$ confidence interval $[95 \% \mathrm{CI}]-8.5$ to -6.84 ; standard error of the difference [SED] 0.408), the mean number of basic laparoscopic operations ( 3.17 vs 6.94 cases per month; $P<0.0001$; $95 \%$ CI -4.096 to -3.444 ; SED 0.165), the mean number of advanced laparoscopic operations ( 0 vs $3.89 ; P<0.0001)$, the number of teams undertaking unselected laparoscopic operations ( 2 vs 5), and the number of teams independently performing advanced laparoscopic operations ( 0 vs 4 ).

Conclusion: At this facility, we have demonstrated a significant increase in laparoscopic case volume and complexity when partnerships were formed between the UWI and this serviceoriented hospital. Continued cross-fertilization and distribution of skill sets across the surgical community can reasonably be expected. We also identified maneuvers that can be used as a template to build laparoscopic services in other service-oriented hospitals in developing nations.

Keywords: laparoscopy, Trinidad, minimal, invasive, endoscopy

\section{Introduction}

Shortly after Eric Muhe performed the first laparoscopic cholecystectomy in 1985, the volume and complexity of laparoscopic operations increased dramatically across the globe. This "laparoscopic revolution" was fueled by advancements in hardware, instrumentation, and technology. However, the Caribbean did not follow the global trend toward laparoscopy. ${ }^{2}$ As an example, only $23 \%$ of all cholecystectomies were attempted by the laparoscopic approach in the most populous country in the Englishspeaking Caribbean in the year 2013. ${ }^{3}$ A similar situation existed in most Caribbean countries, with many offering no laparoscopy at all. ${ }^{4}$
Correspondence: Shamir O Cawich Department of Clinical Surgical Sciences, University of the West Indies, St Augustine, Trinidad and Tobago Tel +l 8686229909 Email socawich@hotmail.com 
This situation existed because most Caribbean countries were low- or middle-income nations that did not have the financial resources to support laparoscopic practice. ${ }^{2,4}$ There were also many "self-imposed obstacles" such as deficiencies in surgical leadership, ${ }^{5}$ lack of prioritization by policy makers, 2,5 and the "sole practitioner culture" that prevailed in the Caribbean. This led to high rates of emigration of skilled health care workers, ${ }^{7}$ compounding the deficiencies. As a result, laparoscopic practice in the Caribbean lagged behind global trends by more than two decades. ${ }^{2}$ Even when laparoscopic operations were performed, they were limited to a few facilities scattered across the region.

These challenges are not limited to the Caribbean. There are similar lags in laparoscopic surgery in many developing countries in Latin America, Asia, and Sub-Saharan Africa. ${ }^{8-12}$ The importance of these data is put into context when we consider that the cumulative population of the developing world is $\sim 2$ billion persons. ${ }^{13}$

In 2013, surgical leaders in Trinidad and Tobago recognized the need to promote laparoscopic practice. They attempted to achieve this by encouraging a partnership between the University of the West Indies (UWI) School of Medicine and a service-oriented public hospital. We sought to examine the effect this initiative had on laparoscopic practice.

\section{Materials and methods}

Ethical approval for this study was granted by the Chief of Staff Office at the General Hospital in the Port of Spain, who did not require that written informed consent be obtained from each patient, as this study was a retrospective review of data.

Trinidad and Tobago is the second largest English-speaking Caribbean Island, with a population of $1,317,714$ persons. ${ }^{14}$ The Government provides health care through a network of public facilities under the auspices of the Ministry of Health (MOH).$^{15}$ The Port of Spain General Hospital (POSGH) is one such public facility that serves a catchment of $\sim 675,000$ persons. ${ }^{15}$ At the commencement of the study period, the surgical department at the POSGH comprised four surgical teams, each headed by at least one fully trained consultant surgeon and a team of medical officers at three-tiered levels: 1) interns who were within 1 year of their basic medical degree, 2) house officers who ranged from 2 to 5 years post-basic medical degree, and 3) registrars who had some training in surgery but were not yet competent for independent practice.

Up to the year 2013, few basic laparoscopic operations were performed at the POSGH. Having recognized the need for improvement, surgical leaders approached the UWI - the only university offering postgraduate surgical training in the Caribbean - and formed a common-interest group with a mandate to promote laparoscopic practice. This common-interest group then approached the $\mathrm{MOH}$ and proposed a strategy to promote laparoscopy. The $\mathrm{MOH}$ recognized that this was beneficial and agreed to focus initial efforts at a single location - the POSGH.

On August 1, 2013, the UWI and MOH agreed to enter into a partnership by creating a new surgical team with specific mandates to optimize postgraduate teaching in minimally invasive surgery and to promote laparoscopic surgical practice. This "UWI team" had a similar staff complement to the existing service-oriented teams, but it was staffed by UWI personnel, including a consultant surgeon and postgraduate surgical residents at two staff grades: house officers and registrars. The UWI agreed to remunerate their staff, with no monetary input from the $\mathrm{MOH}$. The underlying premise was that clinical exposure was necessary to train postgraduate students in technical and clinical aspects of surgery. The UWI agreed to a temporary commitment initially for 3 years, with the possibility for renewal based on outcomes. It was hoped that this period would allow sufficient case numbers to accrue to evaluate outcomes and sufficient training time to make lasting changes in clinical practice among existing surgical teams.

There was no immediate investment or change in equipment, hospital beds, ICU beds, or operating room space. An existing operating list was simply reallocated from another service to the new UWI team. The hospital was already in possession of basic laparoscopic equipment (two graspers, two needle holders, suction and cautery hook) and a laparoscopic hardware tower. No investment was made to purchase additional instruments or hardware. We negotiated with local distributors to provide laparoscopic consumables on consignment. The patients were occasionally asked to purchase the necessary consumables directly from the distributors for use in their operations, when necessary. The local distributors found this acceptable since their interests would be served if the volume of laparoscopic operations would rise, increasing their sales in the long term. Therefore, the UWI team was introduced with limited change in existing conditions, resources or equipment.

This study sought to examine the impact of the UWI/MOH partnership on surgical practice at the POSGH. We secured permission to audit hospital records over a period of 3 years from January 1, 2012 to January 30, 2015. This period was chosen to evaluate 18 months before and after introduction of the UWI team. Operating room registers were reviewed to identify all patients who had laparoscopic operations. The hospital records of these patients were retrieved, data extracted and entered into an Excel database containing the following variables: patient demographics, number of procedures, type 
of operation, surgeon demographics, operative outcomes, morbidity, and mortality. We divided laparoscopic operations into two categories: basic laparoscopic operations including diagnostic laparoscopies, appendectomies, cholecystectomies, and inguinal hernia repairs. All other operations were considered advanced laparoscopic operations.

The data collected were entered into a Microsoft Excel worksheet. The data were divided into two groups: Period 1 included operations performed before introduction of the UWI team (January 1, 2012, to July 31, 2013); Period 2 included operations performed after introduction of the UWI team (August 1, 2013, to January 30, 2015). The data were then analyzed using SPSS version 12.0. Cross tabulations were made between individual operations using Pearson's chi square tests for comparisons. The total number of basic operations and advanced operations performed in each period was compared using chi square statistics and Fisher's exact tests. Significance was considered present with a two-tailed $P$-value $<0.05$.

\section{Results}

Over the 3-year study period, there were 252 laparoscopic operations performed at the POSGH. After introduction of the UWI team, the mean number of unselected laparoscopic operations significantly increased from 3.17 to 10.83 cases per month $(P<0.001 ; 95 \%$ confidence interval $[95 \% \mathrm{CI}]-8.5$ to -6.84 ; standard error of the difference [SED] 0.408). This is demonstrated in Figure 1.
Table 1 outlines the number and nature of operations performed during the study period. The total number of basic operations increased 2.2-fold, from 57 operations in Period 1 to 125 in Period 2. The mean number of basic operations also increased after introduction of the UWI team from 3.17 cases to 6.94 cases per month $(P<0.0001 ; 95 \% \mathrm{CI}-4.096$ to -3.444; SED 0.165).

A similar trend occurred with advanced laparoscopic operations where the mean number of cases performed each month increased from 0 during Period 1 to 3.89 during Period $2(P<0.0001)$.

We noticed another interesting finding when the data were analyzed. In Period 1, there were two surgical teams performing laparoscopic operations at this facility. However, all five surgical teams were performing laparoscopic operations in Period 2. More importantly, four of the five teams progressed to the point where they were independently performing advanced operations including colectomies, ventral hernia repairs, and Heller's myotomies.

The surgical outcomes for these operations were also evaluated. Table 2 lists the perioperative morbidity, operative mortality, and conversion rates for each basic laparoscopic operation performed. The surgical outcomes for all basic laparoscopic operations were found to be within acceptable international standards. When the surgical outcomes of all unselected basic operations were compared between Period 1 and Period 2, there was no statistical difference in the

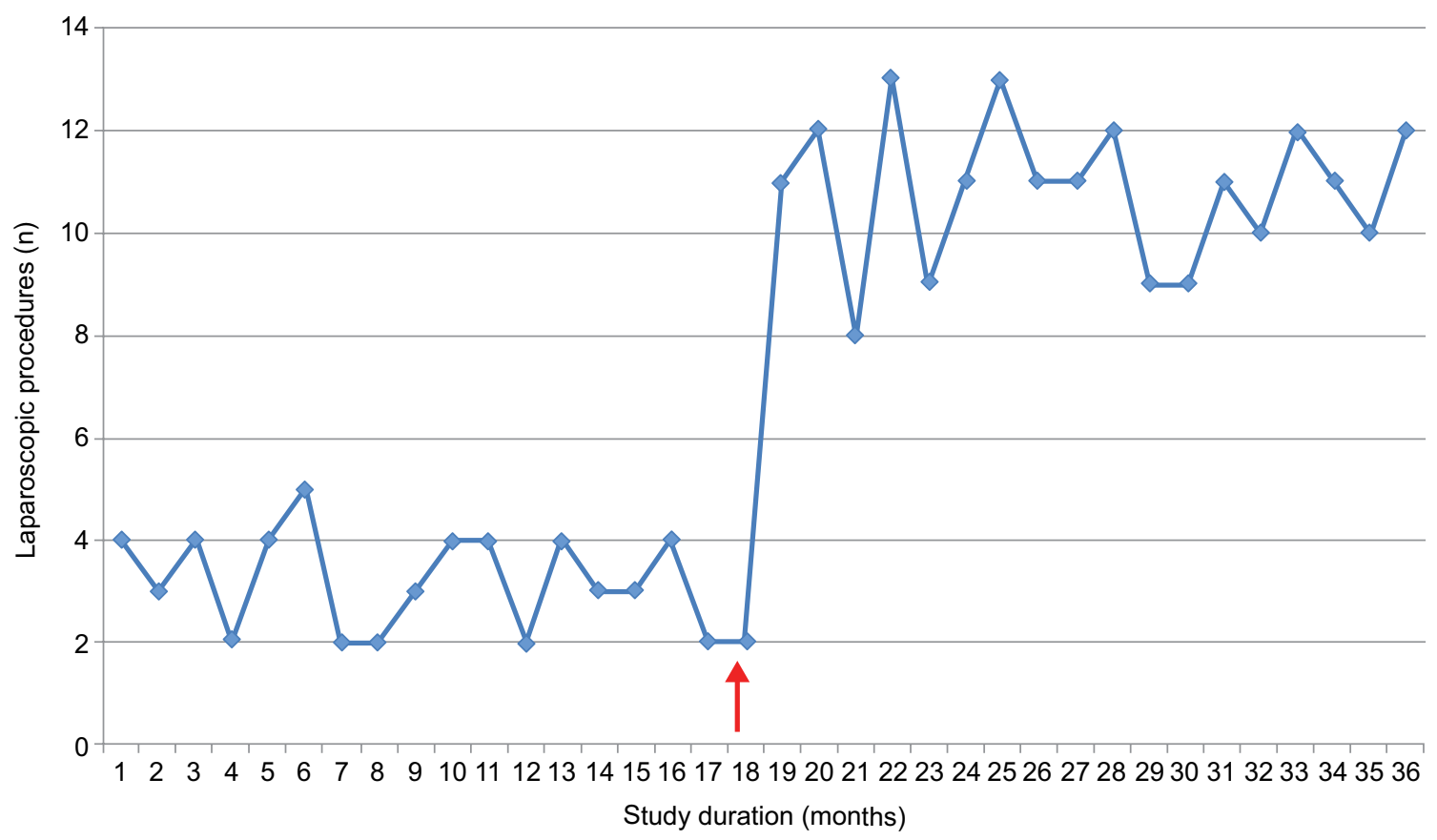

Figure I A graph showing the number of unselected laparoscopic procedures during the study period on a monthly basis. Note: Red arrow marks the introduction of a University of the West Indies surgical team to the Port of Spain General Hospital in Trinidad and Tobago. 
Table I Minimally invasive surgery abdominal operations performed at the Port of Spain General Hospital

\begin{tabular}{|c|c|c|c|}
\hline Name of procedure & Period I & Period 2 & $P$-value \\
\hline \multicolumn{4}{|l|}{ Basic laparoscopic operations } \\
\hline - Cholecystectomy & 53 & 82 & \\
\hline - Appendectomy & 4 & 16 & \\
\hline - Inguinal TAPP repair & 0 & 18 & \\
\hline - Inguinal TEP repair & 0 & 9 & \\
\hline Total basic operations & 57 & 125 & \\
\hline Mean number per month & 3.17 & 6.94 & $<0.0001$ \\
\hline Standard deviation & 0.985 & 1.05 & \\
\hline Standard error of mean & 0.131 & 0.094 & \\
\hline \multicolumn{4}{|l|}{ Advanced laparoscopic operations } \\
\hline - Gastrectomy & 0 & 1 & \\
\hline - Colectomy & 0 & 9 & \\
\hline - Liver resections & 0 & 4 & \\
\hline - Resection of pancreas and/or spleen & 0 & 2 & \\
\hline - Heller's myotomy & 0 & 2 & \\
\hline - Diaphragmatic hernia repair & 0 & 2 & \\
\hline - Ventral hernia repair & 0 & 14 & \\
\hline Total advanced operations & 0 & 70 & \\
\hline Mean number per month & $N / A$ & 3.889 & $<0.0001$ \\
\hline Standard deviation & $N / A$ & 0.832 & \\
\hline Standard error of mean & $N / A$ & 0.099 & \\
\hline
\end{tabular}

Notes: Period I: January I, 2012 to July 31, 2013. Period 2: August I, 2013 to January 30, 2015.

Abbreviations: N/A, not applicable; TAPP, trans-abdominal pre-peritoneal repair; TEP, totally extra-peritoneal repair.

Table 2 Outcomes of basic minimally invasive surgery abdominal operations performed at the Port of Spain General Hospital

\begin{tabular}{|c|c|c|c|}
\hline Procedure & Period I & Period 2 & Details \\
\hline Cholecystecomy & Period $\mathrm{I}=53$ & Period $2=82$ & N/A \\
\hline - Morbidity & I/53 (I.9\%) & 0 & Bile leak (I) \\
\hline - Mortality & 0 & 0 & $\mathrm{~N} / \mathrm{A}$ \\
\hline - Conversions & $3 / 53(5.7 \%)$ & 0 & N/A \\
\hline Appendectomy & Period $\mathrm{I}=4$ & Period 2= 16 & N/A \\
\hline - Morbidity & 0 & 0 & $\mathrm{~N} / \mathrm{A}$ \\
\hline - Mortality & 0 & 0 & $\mathrm{~N} / \mathrm{A}$ \\
\hline - Conversions & I (25\%) & 0 & Unspecified \\
\hline $\begin{array}{l}\text { Inguinal hernia } \\
\text { repair }\end{array}$ & Period $\mathrm{I}=0$ & Period 2=27 & N/A \\
\hline - Morbidity & $\mathrm{N} / \mathrm{A}$ & 3 (II.1\%) & $\begin{array}{l}\text { Surgical site } \\
\text { infection (2), } \\
\text { vascular injury (I) }\end{array}$ \\
\hline - Mortality & $\mathrm{N} / \mathrm{A}$ & 0 & $\mathrm{~N} / \mathrm{A}$ \\
\hline - Conversions & N/A & 0 & N/A \\
\hline $\begin{array}{l}\text { All basic } \\
\text { operations }\end{array}$ & Period $\mathrm{I}=57$ & Period 2 $=125$ & $P$-value \\
\hline - Morbidity & I/57 (1.8\%) & $3 / 125(2.4 \%)$ & 1.00 \\
\hline - Mortality & 0 & 0 & 1.00 \\
\hline - Conversions & 4/57 (7\%) & 0 & 0.3108 \\
\hline
\end{tabular}

Notes: Period I: January I, 2012 to July 31, 2013. Period 2: August I, 2013 to January 30, 2015.

Abbreviation: N/A, not applicable.

operative morbidity (1.8\% vs $2.4 \%$, respectively; $P 1.00)$, perioperative mortality ( 0 vs 0$)$, and conversion rates $(7 \%$ vs 0 , respectively; $P$ 0.3108).
Table 3 lists the perioperative morbidity, operative mortality, and conversion rates for each advanced laparoscopic operation during the study periods. Since there were no advanced laparoscopic operations performed during Period 1, statistical comparisons could not be made. However, the operative mortality $(1.4 \%)$, perioperative morbidity $(8.6 \%)$, and conversion rates $(2.9 \%)$ for all advanced laparoscopic operations performed during Period 2 were found to be within acceptable international standards.

Table 3 Outcomes of advanced minimally invasive surgery operations performed at the Port of Spain General Hospital

\begin{tabular}{|c|c|c|c|}
\hline Procedure & Period I & Period 2 & Details \\
\hline Gastrectomy & Period $\mathrm{I}=0$ & Period 2= I & N/A \\
\hline - Morbidity & N/A & 0 & N/A \\
\hline - Mortality & N/A & 0 & $\mathrm{~N} / \mathrm{A}$ \\
\hline - Conversions & N/A & 0 & $\mathrm{~N} / \mathrm{A}$ \\
\hline Colectomy & Period $\mathrm{I}=0$ & Period 2=9 & N/A \\
\hline - Morbidity & N/A & I/9 (II.I\%) & $\begin{array}{l}\text { Surgical site } \\
\text { infection (I) }\end{array}$ \\
\hline - Mortality & N/A & 0 & N/A \\
\hline - Conversions & N/A & 0 & $\mathrm{~N} / \mathrm{A}$ \\
\hline Liver resection & Period $\mathrm{I}=0$ & Period 2=4 & N/A \\
\hline - Morbidity & N/A & 2 & $\begin{array}{l}\text { Bleeding (I), } \\
\text { myocardial } \\
\text { infarction (I) }\end{array}$ \\
\hline - Mortality & N/A & 1 & $\begin{array}{l}\text { Myocardial } \\
\text { infarction (I) }\end{array}$ \\
\hline - Conversions & N/A & $\mathrm{I}$ & Bleeding (I) \\
\hline $\begin{array}{l}\text { Pancreatic/spleen } \\
\text { resection }\end{array}$ & Period $\mathrm{I}=0$ & Period 2=2 & N/A \\
\hline - Morbidity & $N / A$ & 1 & Bleeding (I) \\
\hline - Mortality & $\mathrm{N} / \mathrm{A}$ & 0 & N/A \\
\hline - Conversions & N/A & I & Bleeding (I) \\
\hline Heller's myotomy & Period $\mathrm{I}=0$ & Period 2=2 & N/A \\
\hline - Morbidity & $\mathrm{N} / \mathrm{A}$ & I & $\begin{array}{l}\text { Esophageal } \\
\text { leak (I) }\end{array}$ \\
\hline - Mortality & N/A & 0 & $\mathrm{~N} / \mathrm{A}$ \\
\hline - Conversions & N/A & 0 & N/A \\
\hline $\begin{array}{l}\text { Diaphragmatic } \\
\text { hernia }\end{array}$ & Period $\mathrm{I}=0$ & Period 2=2 & N/A \\
\hline - Morbidity & N/A & 0 & $\mathrm{~N} / \mathrm{A}$ \\
\hline - Mortality & N/A & 0 & $\mathrm{~N} / \mathrm{A}$ \\
\hline - Conversions & N/A & 0 & $\mathrm{~N} / \mathrm{A}$ \\
\hline Ventral hernia & Period $\mathrm{I}=0$ & Period 2= 14 & N/A \\
\hline
\end{tabular}

repair

- Morbidity

N/A

$$
\text { I }
$$

Surgical site infection (I)

- Mortality

- Conversions

$$
\text { N/A }
$$

N/A

N/A

All advanced operations

- Morbidity

Period $\mathrm{I}=0$

0

N/A

- Mortality

\section{N/A}

Period 2=70

$P$-value

- Conversions

N/A

$6 / 70(8.6 \%)$

$1 / 70(1.4 \%)$

N/A

N/A $2 / 70(2.9 \%)$

Notes: Period I: January I, 2012 to July 31, 2013. Period 2: August I, 2013 to January 30, 2015.

Abbreviation: N/A, not applicable. 


\section{Discussion}

There are numerous obstacles to the advancement of laparoscopy in the Caribbean, including negative attitudes toward laparoscopy, ${ }^{2,5,16}$ equipment deficiencies, ${ }^{2}$ financial constraints, ${ }^{2,17}$ ineffective leadership, ${ }^{5,18}$ and high demand for operating time and lists. ${ }^{3}$ The POSGH was a typical Caribbean hospital where these factors were in play, limiting laparoscopic surgical practice.

This study demonstrates a beneficial impact from the UWI/MOH partnership, with a significant increase in the number and complexity of laparoscopic operations being performed despite minimal change in resources, staffing, equipment, postoperative support and availability of operating lists. Many of these operations were performed for the very first time in this facility: single incision laparoscopic surgery cholecystectomy, pancreatic cystogastrostomy, colectomies, ventral hernia repairs, hepatectomies, pancreatectomies, and splenectomies were all performed for the first time at the POSGH by the UWI team within the study period.

We acknowledge that there are limitations to this study. For example, we could not control for confounders during the study period, such as additional surgeon training, attitudes of nursing/support staff, rotations of junior doctors, availability of operating lists, consumables and/or support services. It could be argued that these may introduce bias if they were present. Not withstanding this, it is clear that there has been a positive impact on this service-oriented public hospital.

We attempted to analyze and document our experiences so that this model can be used as a template in other serviceoriented hospitals across the Caribbean. We define eight steps that we used to achieve these goals (Table 4).

Table 4 Steps to successfully implement a functional minimally invasive surgery (MIS) service

Step I Identify a common-interest lobby group

Although these ideas may start from few individuals, we must recognize that an individual can make little change alone. Therefore, common-interest groups should be identified to make proposals together as a lobby group.

- The lobby group must be organized.

- The administrative roles must be defined.

- A clear mission statement should be devised so that the goals are unified.

Step 2 Perform a feasibility study

- Perform an audit to evaluate existing clinical practice.

- Include an evaluation of the existing facilities.

- Research the existing data from similar environments in support of MIS practice.

- Define the existing limitations that must be addressed in order to realize these goals.

Step 3 Engage all stakeholders

- Stakeholder buy-in is important so that all stakeholders feel to be a part of the change.

- Ensure that there is some consultation with all members to the health care team who will encounter MIS practice: nursing staff, physician grade staff, operating theater scrub technicians, and administrative grade staff.

- This process creates a team spirit and resulted in all stakeholders aiming for a unified goal.

Step 4 Forge partnerships with policy makers

- Lobby groups must demonstrate a firm commitment in order to forge partnerships with policy makers.

Step 5 Solicit support from industry/sponsors

- Hold dialog with local distributors soliciting donations of or assistance with instruments and consumables for MIS practice.

- Attempt to organize acquisition of consumables on consignment.

Step 6 Cross-fertilization so that all stakeholders feel to be part of the process and can see tangible benefits

- Cross-fertilization of skill sets is important to ensure that all stakeholders feel like a part of the change.

- Training in leadership skills is indispensable to foster good working relationships.

- Practicing Caribbean surgeons should be invited as proctors in order to share experiences and technical modifications in order to develop sustainable MIS practice.

- In-service proctoring of University of the West Indies staff, residents, and attending grade surgeons is important because most Caribbean surgeons have adapted their MIS techniques to suit their practice environment.

Step $7 \quad$ Perform regular audits

- This will identify the progress of and benefits with a change in clinical practice.

- It may also identify pitfalls that require correction to achieve high standards of clinical practice.

Step 8 Include continuing medical education as a part of the priorities

- Constant stimulation is important to maintain interest in laparoscopy.

- Ensure activities are in place for continued medical education.

- Consider organizing regular workshops with visiting MIS proctors.

- Regional surgeons should be considered as proctors to teach techniques that are suited to the local environment, rather than relying on techniques from resource-rich environments that relied heavily on instrumentation and consumables.

- Consider organizing hands-on workshops to allow local surgeons to become proficient at laparoscopic suturing, tissue handling, and other modifications that are suited to low-resource settings. 
1. Formation of a common-interest group: Surgical leaders not only recognized a need for improvement but also recognized that prior attempts to initiate change as individuals were traditionally greeted with resistance. On this occasion, they planned a different approach, soliciting the UWI to seek support for this initiative. It was easier for the common-interest lobby group to gain audience with administrators at the $\mathrm{MOH}$ once it was endorsed by the UWI.

We suggest identifying suitable individuals to form common-interest groups to lobby for change, rather than individual efforts. Additionally, support from medical training institutions has the positive effect of adding weight to the lobby groups. In the Caribbean, this can be achieved by dialog with any of the three regional bodies focusing on surgical education and advancement of surgery: the UWI - a university that trains postgraduate surgeons from all English-speaking Caribbean countries, the Caribbean College of Surgeons - a professional association of surgical leaders from across the region, and the Caribbean Society of Endo-Laparoscopic Surgeons - a professional association of advanced laparoscopic surgeons in Caribbean practice.

2. Feasibility study: Although the common-interest lobby group gained audience with policy makers to discuss the introduction of laparoscopic services, without being able to demonstrate existing deficits, the successive steps were slow. Only after we carried out an audit at the POSGH, was it acknowledged that laparoscopic operations were performed at low volumes (mean of three basic operations per month). Only then did policy makers become keen on implementing the service. The lobby team also supported their plan by accruing regional data to demonstrate the benefits of laparoscopy in Caribbean nations. ${ }^{2,16,17,19-24}$

We suggest that an audit of existing practice is indispensable as a part of the feasibility study. This should be completed before meeting with policy makers. These data, along with regional data from other Caribbean territories, should be at hand to support the initiative.

3. Engage all stakeholders: Success requires stakeholder buy-in because there is the potential for persons to erect barriers when they do not feel to be involved in a part of the change. ${ }^{17,25}$ Cognizant of this, we informally approached the nursing, anesthetic, and operating room support staff to discuss their views on laparoscopic surgery at the POSGH. We found that the process of engagement created a team spirit and resulted in all stakeholders aiming for a unified goal.
We recommend a process of consultation with all persons who will become involved in laparoscopic surgery. This includes all members of the health care team including operating room technicians, nursing, medical, and administrative staff.

4. Create partnerships with policy makers: After gaining audience with administrators and demonstrating existing deficiencies at the POSGH, there was still little momentum to implement a functional laparoscopic service. The UWI lobby group recognized the need to stimulate action from policy makers. Therefore, the UWI made a bold move by volunteering to provide attending grade staff if the MOH put policy in place to create a new "UWI team" geared specifically to laparoscopic surgery and teaching. The UWI further committed to commence a postgraduate program in surgery in the medium term at the POSGH. This would involve residents' rotations through the UWI team. The team would also run elective clinics and take emergency calls similar to the existing surgical teams, now on a 1-in-5 basis. Once the UWI demonstrated a commitment, a partnership was created between these two stakeholders.

5. Solicit support from industry/sponsors: Unfortunately, immediate plans to acquire laparoscopic hardware and instrumentation could not be met and the UWI team was expected to function with existing equipment. The immediate obstacle at this point was the lack of instrumentation. The current hardware included a first-generation laparoscopic stack, but the necessary instruments were unavailable. Therefore, the UWI approached local distributors soliciting assistance in this regard. Once the local distributors realized that supporting laparoscopy would be advantageous in the long term, they were willing to loan the necessary instrumentation for laparoscopic practice to develop.

The cost of consumables for minimally invasive surgery has been a major limitation across the Caribbean. ${ }^{2}$ Laparoscopic surgeons in the Caribbean have adapted by using re-usable trocars/instruments, ${ }^{19-22}$ becoming proficient at laparoscopic suturing ${ }^{24}$ instead of relying on staples or clips and adapting their surgical techniques to suit low-resource settings. ${ }^{22-24}$ It is important that the industry realize that surgical practice in this environment differs from that in developed countries in order to tailor the nature of business practices and support. It is imperative that practicing Caribbean surgeons share these experiences and modifications in order to develop sustainable practice. 
6. Cross-fertilization of experience and skill sets: It was very important that the UWI team did not function in isolation because all stakeholders should be part of the process. Therefore, the UWI team ensured that there was cross-fertilization of experience and skill sets by two means. First, policy was changed to require junior staff to rotate through all services, thereby ensuring exposure to laparoscopy during rotations on the UWI team.

Second, the UWI trained their staff in leadership skills in order to ensure that good working relationships were always maintained between the surgical teams. The benefit of fostering good inter-personal working relationships was that the UWI team surgeons were regularly invited to operate with the service-oriented teams, thereby sharing their experience, techniques, and skill sets.

The cross-fertilization that occurred as a result of these two maneuvers was evident. In Period 1, only two surgical teams were performing basic laparoscopic procedures at POSGH. In Period 2, all five surgical teams were performing laparoscopic operations, with four performing advanced operations. We believe this was due to the educational focus, with the UWI staff proctoring postgraduate residents and attending grade surgeons who were not exposed to laparoscopic practice. It has already been noted that most Caribbean surgeons have adapted their techniques to suit their practice environment. ${ }^{19-24}$ Therefore, this type of cross-fertilization from practicing Caribbean surgeons sharing these experiences and technical modifications is critical to develop sustainable laparoscopic practice.

7. Regular audit: An audit was carried out 18 months after introduction of the UWI team. We have already stated the potential limitations of our study, but we also believe that the demonstrable benefits were largely due to the UWI initiative since there was little change otherwise. However, without regular audits, the benefits would not be recognized.

We suggest performing regular practice audits to assess clinical practice. This is also a good way to identify pitfalls that may need correction to achieve high standards of clinical practice.

8. Prioritize continued medical education: During a period of rapid change/progress, general interest becomes peaked and there is generally good support as change is evident. This was observed in the initial stages of the UWI/MOH partnership. However, we expect that at some point there will be stagnation, unless there is constant stimulation. This can easily be achieved by activities designed for continued medical education. At the POSGH, the UWI team spearheaded regular workshops moderated by visiting experts semiannually in order to maintain interest in laparoscopy.

It was equally important to involve regional surgeons as proctors because local surgeons would learn techniques that were well suited to their environment, rather than using techniques from resource-rich environments that relied heavily on instrumentation and consumables. There are several educational bodies that currently partner with the UWI, including the Caribbean College of Surgeons and the Caribbean Society of Endo-Laparoscopic Surgeons. These societies should be involved to support the laparoscopic movement.

This initiative has been greeted with remarkable success, demonstrating statistically significant increases in the volume and complexity of laparoscopic operations being performed. This model can be used as a template in facilities in other countries across the region. Table 2 lists the important steps to follow in this model to implement functional laparoscopic services in other Caribbean nations.

\section{Conclusion}

There is a mutually beneficial outcome when partnerships are formed between tertiary surgical educational institutions and service-oriented hospital departments. Specifically in the Caribbean, we have demonstrated a significant increase in laparoscopic case volume and complexity when the UWI partnered with this service-oriented hospital. Cross-fertilization and distribution of skill sets across the nation are also expected. The maneuvers used here can be used as a template to build laparoscopic services in other developing nations.

\section{Disclosure}

The authors report no conflicts of interest in this work.

\section{References}

1. Reynolds W. The first laparoscopic cholecystectomy. JSLS. 2001;5(1): 89-94.

2. Dan D, Nararynsingh V, Cawich SO, Jonnalagadda R. The history of laparoscopic general surgery in the Caribbean. West Indian Med $J$. 2012;61(4):465-469.

3. Cawich SO, Mohanty SK, Albert M, Simpson LK, Bonadie KO, Dapri G. Single port laparoscopic cholecystectomy with straight instruments: a national audit in Jamaica. Caribb Med J. 2012;74(2):5-7.

4. Naraynsingh V, Bahadursingh S, Maharaj R, Harnarayan P, Cawich SO Surgery in the West Indies: a perspective from Trinidad. Curr Med Res Pract. 2014;4:1126-1129.

5. Cawich SO, Harding HE, Crandon IW, et al. Leadership in surgery for public sector hospitals in Jamaica: strategies in the operating room. Perman J. 2013;17(3):121-125. 
6. Cawich SO, Johnson PB, Shah S, et al. The multidisciplinary team approach to hepatobiliary diseases: a working model in the Caribbean setting. J Multidiscip Healthc. 2014;7:227-230.

7. Taylor R. Opportunities for partnerships between CAGS and surgical programs in the developing world [report to CAGS]. 2000. Available from: https://www.cags-accg.ca/docs/Taylor_-_CAGS_report_2000. DOC. Accessed September 28, 2016.

8. Amin AT, Ahmed BM, Khallaf SM. Safety and feasibility of laparoscopic colorectal surgery for cancer at a tertiary center in a developing country: Egypt as an example. J Egypt Natl Canc Inst. 2015;27(2):91-95.

9. Long KL, Spears C, Kenady DE, Roth JS. Implementation of a low-cost laparoscopic skills curriculum in a third-world setting. J Surg Educ. 2014;71(6):860-864.

10. Orr KB. Laparoscopy in third-world countries. Bull Am Coll Surg. 2008;93(12):46

11. Cadiere GB, Himpens J, Bruyns J. Laparoscopic surgery and the third world. Surg Endosc. 1996;10(10):957-958.

12. Sharma AK, Rangan HK, Choubey RP. Mini-lap cholecystectomy: a viable alternative to laparoscopic cholecystectomy for the Third World? Aust NZJ Surg. 1998;68(11):774-777.

13. Haub C. World Population Data Sheet: Population Trends; 2012. United Nations Population Division, World Population Prospects: The 2010 Revision. Available from: http://www.prb.org/Publications/Data sheets/2012/world-population-data-sheet/fact-sheet-world-population. aspx. Accessed June 2, 2015.

14. Central Statistical Office. Ministry of Planning and Development. Government of the Republic of Trinidad \& Tobago. Population Statistics; 2000-2010. Available from: http://www.planning.gov.tt/sites/ default/files/content/mediacentre/documents/Trinidad-and-TobagoDemographic-Report-2011.pdf. Accessed September 28, 2016.

15. Government of Republic of Trinidad \& Tobago/Ministry of Health. Regional Health Authorities. Available from: www.health.gov.tt/sitepages/default.aspx?id=6. Accessed June 2, 2015
16. Cherian JC, Cawich SO, Wilson C, Baker A, Llyod C, Thomas C. Healthcare workers' attitudes toward advancement of minimally invasive surgery practice in Jamaica: a national survey. West Ind Med J. 2012;61(S3):11-12.

17. Wilson CB, Cawich SO, Simpson LK, Baker AJA. Starting a laparoscopic surgery service in a rural community hospital in Jamaica: successes and challenges of the Percy Junor Hospital experience. Caribbean Med J. 2014;76(1):8-11.

18. Cawich SO, Johnson PB, Dan D, Naraynsingh V. Surgical leadership in the time of significant generational diversity. Surgeon. 2014;12:235-236.

19. Cawich SO, Wilson C, Simpson LK, Baker AJA. Stump cholecystitis: laparoscopic completion cholecystectomy with basic laparoscopic equipment in a resource poor setting. Case Report Med. 2014;787631:1-4.

20. Cawich SO, Albert M, Singh Y, et al. Single incision laparoscopic cholecystectomy in the Anglophone Caribbean: a multi centre audit of regional hospitals. Int J Biomed Sci. 2014;10(3):191-195.

21. Cawich SO, Mohanty SK, Simpson LK, Bonadie KO. Is emergent laparoscopic cholecystectomy for acute cholecystitis safe in a low volume resource poor setting? Int J Surg. 2014;12(8):798-802.

22. Cawich SO, Thomas D, Hassranah D, Naraynsingh V. Evolution of single incision laparoscopic cholecystectomy in the Caribbean: toward conventional instruments without working ports. Case Rep Surg. 2014; 164342:1-4

23. Cawich SO, Murphy T, Shah S, et al. Endoscopic transmural drainage of pancreatic pseudocysts: technical challenges in the resource poor setting. Case Rep Gastrointest Med. 2013;942832:1-6.

24. Cawich SO, Mohanty SK, Simpson LK, Ramdass MJ, Naraynsingh V. Is laparoscopic appendectomy safe when performed in a low volume setting? Int J Biomed Sci. 2014;10(1):31-35.

25. United States Department of Health and Human Services. Meaningful use and critical access hospitals: a primer on HIT adoption in the rural health care setting. Health Resources Services. 2010. Available from: http://www.hrsa.gov/healthit/meaningfuluse/meaningfuluseprimer.pdf. Accessed September 28, 2016.
Risk Management and Healthcare Policy

\section{Publish your work in this journal}

Risk Management and Healthcare Policy is an international, peer-reviewed open access journal focusing on all aspects of public health, policy, and preventative measures to promote good health and improve morbidity and mortality in the population. The journal welcomes submitted papers covering original research, basic science, clinical and epidemiological

\section{Dovepress}

studies, reviews and evaluations, guidelines, expert opinion and commentary, case reports and extended reports. The manuscript management system is completely online and includes a very quick and fair peerreview system, which is all easy to use. Visit http://www.dovepress.com/ testimonials.php to read real quotes from published authors. 